\title{
Additive Manufacturing of Salt Hydrates: Primary Process Parameters and Case Study
}

\author{
Markus Brillinger ${ }^{1,2}$, Christian Pichlkastner ${ }^{3}$, Franz Haas $^{2}$, Andreas Trummer ${ }^{3}$, and Muaaz Abdul Hadi ${ }^{1}$ \\ ${ }^{1}$ Pro2Future, Area 4.2 - Cognitive Production Systems, 8010 Graz, Austria \\ ${ }^{2}$ Graz University of Technology, Institute of Production Engineering, 8010 Graz, Austria \\ ${ }^{3}$ Graz University of Technology, Institute of Structural Design, 8010 Graz, Austria
}

\begin{abstract}
This paper pr esents the 1 atest out comes in the field of additive $m$ anufacturing. Som e s alt hydrates as printing materials provide many advantages ( such as good a vailability and low toxic b ehaviour) compared to ot her materials, thus making them $\mathrm{p}$ articularly $\mathrm{s}$ uitable for s pecific ap plications. A layered d eposition $\mathrm{m}$ ethod $\mathrm{f}$ or $\mathrm{s}$ alt hydrates is developed from the binary phase diagram of sodium acetate trihydrate, which is first described mathematically. The experimental results then verify the theoretically described method. Thus, the presented process can also be applied to other salt hydrates which are based on the same physical basic principles. Moreover, this novel process has been termed as Subcooled Liquid Printing (SLP) by the authors.
\end{abstract}

\section{Introduction}

The global $\mathrm{m}$ arket $\mathrm{s}$ ize of additive $\mathrm{m}$ anufacturing $\mathrm{h}$ as increased significantly in recent years [1], [2]. This is due to the potential of producing complex geometries in a reasonable time at an affordable cost [3], [4]. As a result, the i ndividualization of $\mathrm{p}$ roducts ( mass $\mathrm{c}$ ustomization) can $n$ ow b e r ealized without $t$ he $n$ eed for co nsiderable additional effort, and the time to market for new products has $b$ een significantly $r$ educed [5], [6]. D uring the $p$ ast few years, $s$ ome ad ditive $m$ anufacturing $t$ echnologies, such as the FDM, S LM and SLA p rocesses, have e ven been $\mathrm{s}$ uperior o ver co nventional $\mathrm{m}$ anufacturing technologies (e.g. mold making). For mold making in the case of highly c omplex ge ometry 1 ike u ndercuts, t he question of demolding comes into focus. Solvation is one common method $\mathrm{f}$ or $\mathrm{r}$ emoving $\mathrm{t}$ he mold. W ith $\mathrm{t}$ his method, the solvation temperatures of both the casted and the mold material are crucial. The molds of salt hydrates are $\mathrm{s}$ uitable for mineral $\mathrm{b}$ ased cas ting materials s uch a $\mathrm{s}$ concrete d ue to their 1 ow solvable temperatures. To utilize the advantages of ad ditive manufacturing and salt hydrates i $\mathrm{n}$ old $\mathrm{m}$ aking, a new a pproach of additive manufacturing process is developed.

Recent $\mathrm{s}$ tudy i ndicates $\mathrm{t}$ hat $\mathrm{t}$ he o utlining factors $\mathrm{t} o$ expand the field of application for additive manufacturing technologies are using new materials and increasing the speed of the processes [7], [8]. Due to the high specific latent heat, salt hydrates are primarily researched as phase change materials in latent heat storage systems. For instance, space h eating a nd omestic h ot water preparation [9], s olar h eating s ystems [10], and $\mathrm{r}$ adiant floor heating systems [11]. A literature review shows that there is no a dditive manufacturing technology using salt hydrates as printing material. In recent years, only the salt hydrates aqueous sodium chloride and ammonium chloride have been investigated as a novel cold source for the platform [12]. Hence, this paper at tempts to address this 1 ack of $\mathrm{r}$ esearch in $\mathrm{u}$ sing s lat hydrates for ad ditive manufacturing processes.

\section{Material}

In th is section, the materials involved in $\mathrm{t}$ he $\mathrm{n}$ ewly developed ap proach $\mathrm{h}$ as $\mathrm{b}$ een $\mathrm{d}$ escribed. The ch emical composition a nd $\mathrm{s}$ tructure of $\mathrm{s}$ alt hy drates a nd s odium acetate trihydrate has been elaborated. Further references have $b$ een given which illu strates $t$ heir us age $\mathrm{i} n \mathrm{t}$ his additive manufacturing process.

\subsection{Salt hydrates}

A salt hydrate is a crystalline salt molecule that is loosely attached $t \mathrm{o}$ a cer tain $\mathrm{n}$ umber of water molecules. $\mathrm{T}$ he properties such as solvation temperature and toxicity of a salt hydrate (e.g. sodium acetate trihydrate) depend on the crystalline salt molecule a nd the number of a ttached water molecules. Thus, they differ significantly. Sodium acetate tr ihydrate ( SAT) is d istinguished mainly b y the good availability and the low to xic behaviour compared to o ther salt hydrates [13], [14]. Therefore, handling and processing of SAT is viable without any material-specific safety precautions. Hence, this salt hydrate is examined in this paper in more detail. 


\subsection{Sodium Acetate Trihydrate (SAT)}

The chemical structure of S AT contains three molecules of water whereas, sodium acetate (SA) is the anhydrous form o f S AT an d co ntains $\mathrm{n} o$ water molecules. $\mathrm{T}$ he binary $\mathrm{p}$ hase $\mathrm{d}$ iagram o f S A a nd water, as shown i $\mathrm{n}$ figure 1, pr ovides information on $t$ he $s$ tates o $f$ aggregation at $\mathrm{d}$ ifferent $\mathrm{t}$ emperatures an $\mathrm{d}$ aq ueous solution concentrations. [9]

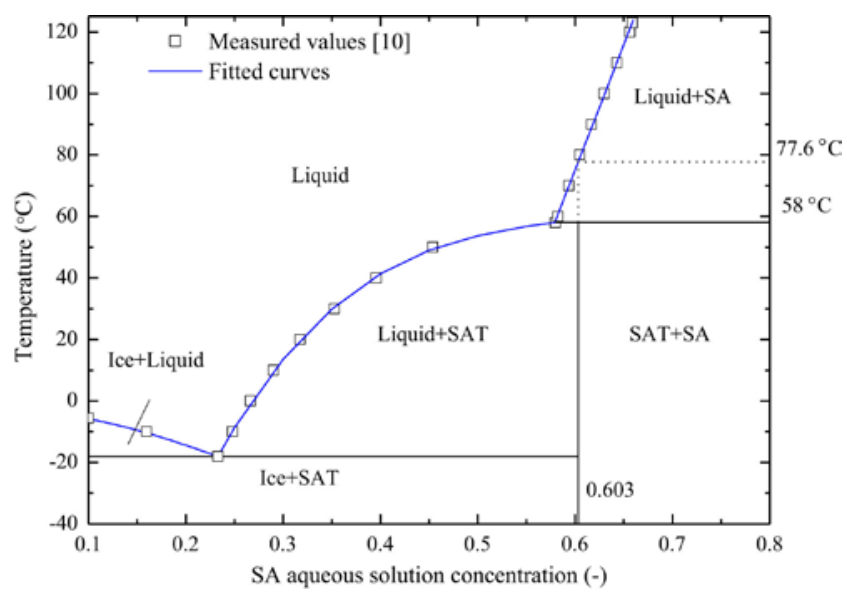

Figure 1. Phase diagram of SA and water [9].

As exhibited in this diagram, o ne a rea in which the SA a queous solution $c$ an a ssume $t$ wo states of aggregation: $\mathrm{t}$ he s table s olid s tate a nd the metastable (subcooled) 1 iquid $\mathrm{s}$ tate ( Liquid $+\mathrm{SAT}$ ) is se en. $\mathrm{T}$ his subcooled s tate of ag gregation can b e co nverted into a stable state of a ggregation by a di sturbance which triggers the crystallization. This property of S A aqueous solution is $u$ sed for an additive manufacturing $p$ rocess. The binary phase diagram shows that there are two main process parameters in the additive manufacturing process: the temperature $T$ and the concentration $w$. The following case s tudy investigates the i nfluence of $t$ emperature, concentration, and other essential process parameters on the properties of the deposited layers.

\section{Process}

In th is $\mathrm{s}$ ection, the th orough $\mathrm{p}$ rocess of $\mathrm{s}$ odium a cetate trihydrate is e laborated. The ex perimental s et-up of the process $\mathrm{i}$ s el ucidated which $\mathrm{i} s$ followed $b$ yt he classification o f $g$ eometry of $t$ he deposited 1 ayer. A mathematical model is then described for the calculation of ideal periodicity length.

\subsection{Experimental setting for depositing layers}

An ex perimental model was s et-up f or a nalysing a nd testing the pr ocess. I $t \mathrm{c}$ onsisted of h eating a nd c ooling systems, $\mathrm{p}$ umps, $\mathrm{t}$ emperature $\mathrm{s}$ ensors, a nd a nozzle. Figures 2 and 3 illustrate the experimental setting used to carry out the case study.

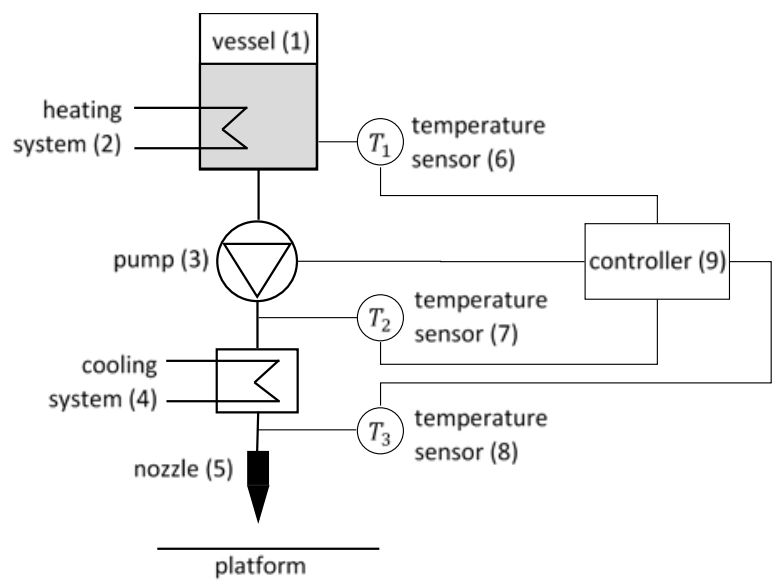

Figure 2. Experimental setting u sing the solidification process of SAT.

First, S AT ( crystalline white $\mathrm{p}$ owder) a nd w ater (liquid) a re mixed in a $\mathrm{v}$ essel ( no. 1) a $\mathrm{ta}$ mbient temperature $\left(T_{1}\right)$ in a d efined co ncentration $w$. U sing a heating system (no. 2) the mixture is heated to $T_{2}$, which is higher than the solvation temperature $T_{\mathrm{s}}$, and it changes into a liquid state, i.e., a solution. This solution is pumped to the cooling system (no. 4), where heat is removed from the solution to cool it $\mathrm{d}$ own from te mperature $T_{2}$ to $T_{3}$, which is s till s lightly a bove the solvation temperature. Subsequently, $t$ he s olution is ej ected as $d$ rops o $\mathrm{r}$ a $\mathrm{j}$ et from a n ozzle o utlet ( no. 5 ). T he t emperature must b e measured throughout the entire process (no. 6, no. 7 and no. 8). The data from these temperature sensors are input into the controller (no. 9), which regulates the flow rate of the pump (no. 3).

Figure 3 describes in detail the crystallization process which occurs after the solution is ejected from the nozzle outlet ( step 1 ). W hile d ropping o nto th e $\mathrm{p}$ latform (distance $h_{\mathrm{nl}}$ ) t he solution c ools d own a nd $t$ urns i nto metastable (but still liquid) state (step 2). The metastable solution i mpacts on a p latform ( step 3 ) an d cr ystallizes rapidly ( step 4). A solid layer (width $w_{1}$ and thickness $t_{1}$ ) is deposited. Due to the crystallization, the latent heat is released an $\mathrm{d} t$ he $\mathrm{t}$ emperature o $\mathrm{ft}$ he $\mathrm{d}$ eposited $\mathrm{l}$ ayer increases. This latent heat must ultimately be discharged into the environment (step 5).

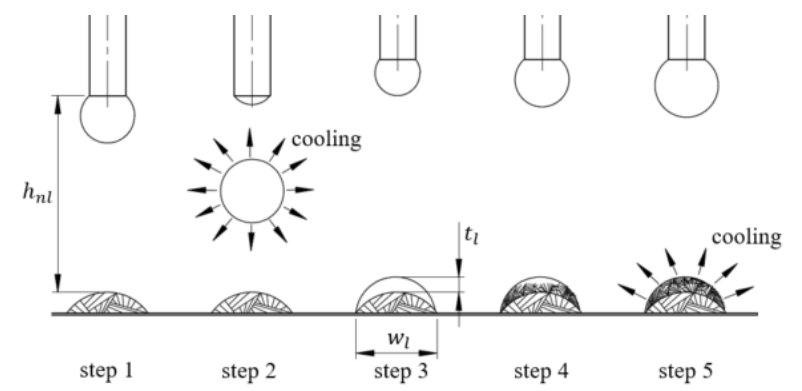

Figure 3. Deposition of solid layers of SAT.

\subsection{Classification o $f t$ he $g$ eometry o $f$ th $e$ deposited layer}

The $d$ eposited 1 ayer at $t$ he $p$ latform can $b$ e cl assified according $t$ o $\mathrm{i}$ ts $\mathrm{g}$ eometry into $\mathrm{c}$ ontiguous a nd $\mathrm{n}$ on- 
contiguous as well as uniform and non-uniform, shown in figure 4 .

uniform structure

Figure 4. Geometrical classification of the deposited layer

While $\mathrm{u}$ niform g eometries ( type 1 an $\mathrm{d} 2$ ) y ield a regular a nd repeatable $d$ eposited layer, contiguous geometries (type 1 and 3 ) ensure bonded layer structures. To de posit bot $\mathrm{h} r$ egular a nd bon ded 1 ayer s tructures, therefore, geometries of type $1 \mathrm{a}$ and $1 \mathrm{~b}$ (layered or dotted structures) are preferable to all other types.

To classify a d eposited layer of type 1 , the properties layer $w$ idth $w_{1}$, la yer periodicity le ngth $l_{1}$ and the 1 ayer thickness $t_{1}$ (illustrated i $\mathrm{n}$ figure 4 ) ar e u sed. These properties depend on the nozzle diameter $d_{\mathrm{n}}$, the distance between nozzle and the deposited layer $h_{\mathrm{nl}}$, the feed rate $v_{\mathrm{f}}$ and the nozzle o utlet velocity $v_{\mathrm{n}}$. These are shown in detail in figure 5 .

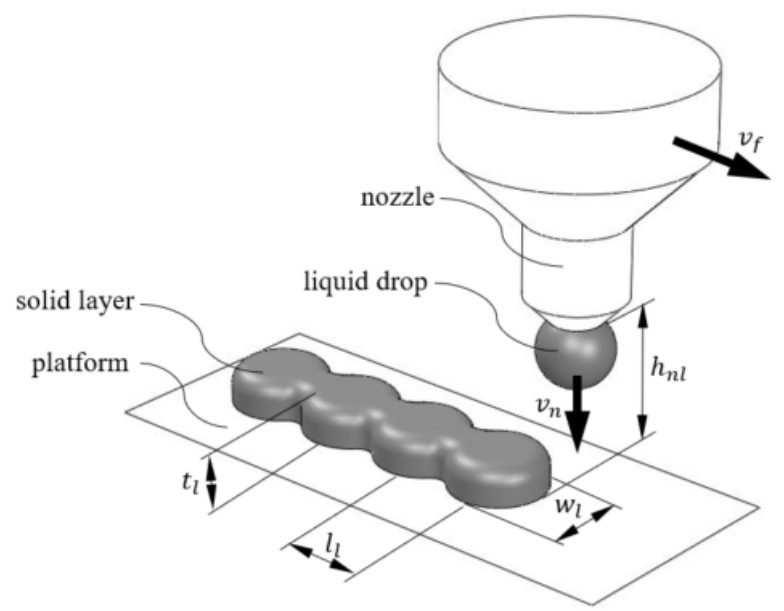

Figure 5. Classification of the deposited layer.

As can be seen in the above figure, the layer width is the maximum dimension of a deposited layer, when measured o rthogonally t o t he f eed d irection. The 1 ayer thickness is the dimension in the direction of the no zzle outlet $v$ elocity. $T$ he la yer p eriodicity le ngth in dicates a $t$ what distance in the feed direction a structure of the layer begins to be repeated. Going forward, in this paper, the layer periodicity length is investigated in more detail.

\subsection{Mathematical model for the layer periodicity length}

For un iform a nd c ontiguous layer s tructures ( type 1 in figure 4 ) the 1 ayer $p$ eriodicity length can b e d erivated theoretically when the droplet is formed at the nozzle via the balance o $\mathrm{ff}$ orces. Also, $\mathrm{t}$ his $\mathrm{d}$ erivation can b e applicable for geometries of type 2 .

The static balance of surface force, weight force, and momentum force are the basis for equation (3.1), which describes the volume of the liquid drop $V_{\text {drop }}$ separating from the nozzle.

$$
V_{\text {drop }}=\frac{d_{n} \pi}{g}\left[\frac{\sigma_{s}}{\rho_{s}}-\frac{d_{n} v_{n}{ }^{2}}{4}\right]
$$

In this equation, $g$ is the gravity acceleration, $\sigma_{\mathrm{s}}$ the surface tension of the solution, and $\rho_{\text {s }}$ the density of the solution.

When $t$ he $c$ ontinuous flow $r$ ate of $t$ he solution generated $b$ y $t$ he $p$ ump i s co rrelated $w$ ith $t$ he $d$ iscrete liquid drops $\mathrm{s}$ eparating $\mathrm{f}$ rom $\mathrm{t}$ he $\mathrm{n}$ ozzle, $\mathrm{t}$ he 1 ayer periodicity 1 ength, ex pressed i n eq uation (3.2), can b e derived.

$$
l_{l}=\frac{V_{\text {drop }} v_{f} 4}{v_{n} d_{n}{ }^{2} \pi}
$$

When combining e quations (3.1) and (3.2), equation (3.3) is formed

$$
l_{l}=\frac{v_{f}}{v_{n} g}\left[\frac{4 \sigma_{s}}{d_{n} \rho_{s}}-v_{n}^{2}\right]
$$

Since $v_{\mathrm{n}}$ has a considerably lower dimension than the first te rm, it can b e n egated. $\mathrm{H}$ ence, ( 3.3) can b e simplified as shown in equation (3.4).

$$
l_{l}=\frac{v_{f}}{v_{n} g} \frac{4 \sigma_{s}}{d_{n} \rho_{s}}
$$

In equation (3.4), the density and the surface tension of $t$ he $s$ alt hy drate $s$ olution de pend s trongly of $t$ he concentration and the temperature [15], [16].

Furthermore, for the dimensionless speed ratio of feed rate $v_{\mathrm{f}}$ and the nozzle outlet velocity $v_{\mathrm{n}}$, the given name $a$ is used.

$$
\alpha=\frac{v_{f}}{v_{n}}
$$

\section{Results and experimental verification}

Using the layer deposition method de veloped above, experiments were carried out to investigate how the process parameters influence the layer periodicity length. Different values $f$ or $t$ he process parameters were investigated, shown in Table 1 below.

Table 1. Process parameters used in the experiments.

\begin{tabular}{|c|c|c|c|}
\hline Process parameter & Min. & Max. & Remark \\
\hline Nozzle diameter $d_{\mathrm{n}}$ & $\begin{array}{c}0.6 \\
\mathrm{~mm}\end{array}$ & $\begin{array}{c}1.5 \\
\mathrm{~mm}\end{array}$ & \\
\hline $\begin{array}{c}\text { Distance nozzle- } \\
\text { platform } h_{\mathrm{nl}}\end{array}$ & \multicolumn{2}{|c|}{$5 \mathrm{~mm}$} & \\
\hline Feed rate $v_{\mathrm{f}}$ & $\begin{array}{c}0.03 \\
\mathrm{~m} / \mathrm{s}\end{array}$ & $\begin{array}{c}0.08 \\
\mathrm{~m} / \mathrm{s}\end{array}$ & \\
& \multicolumn{3}{|l}{} \\
\end{tabular}




\begin{tabular}{|c|c|c|c|}
\hline $\begin{array}{c}\text { Nozzle outlet } \\
\text { velocity } v_{\mathrm{n}}\end{array}$ & $\begin{array}{c}0.09 \\
\mathrm{~m} / \mathrm{s}\end{array}$ & $\begin{array}{c}1.06 \\
\mathrm{~m} / \mathrm{s}\end{array}$ & $\begin{array}{c}\text { The solvation temp. } \\
\text { acc. to figure } 1 \text { is } T_{\mathrm{s}} \\
=58^{\circ} \mathrm{C}\end{array}$ \\
\hline Concentration $w$ & 0.575 & $\begin{array}{c}\text { Ambient temperature } \\
\text { Temperature } T_{1}\end{array}$ & $\begin{array}{c}\text { Approx. } \\
25^{\circ} \mathrm{C}\end{array}$ \\
\hline Temperature $T_{2}$ & $\begin{array}{c}\text { Approx. } \\
80^{\circ} \mathrm{C}\end{array}$ & $\begin{array}{c}\text { Depends on the heat } \\
\text { losses of the exp. } \\
\text { system, shown in } \\
\text { figure } 2\end{array}$ \\
\hline Temperature $T_{3}$ & $60^{\circ} \mathrm{C}$ & $\begin{array}{c}\text { Depends on the } \\
\text { solvation temp. } T_{\mathrm{s}}\end{array}$ \\
\hline
\end{tabular}

The $r$ esults, $i$ llustrated i $n$ Table $2, r$ epresent $t$ he predicted $\mathrm{c}$ ontiguous a nd non -contiguous a $\mathrm{s}$ well a $\mathrm{s}$ uniform and non-uniform structures of the deposited layers with $r$ espect $t$ o the s peed $r$ atio and the distance between nozzle and the deposited layer $h_{\mathrm{nl}}$.

Table 2. Experimental results of the structure of the deposited layers for different speed ratios and distance between nozzle and the deposited layer $h_{\mathrm{nl}}$.

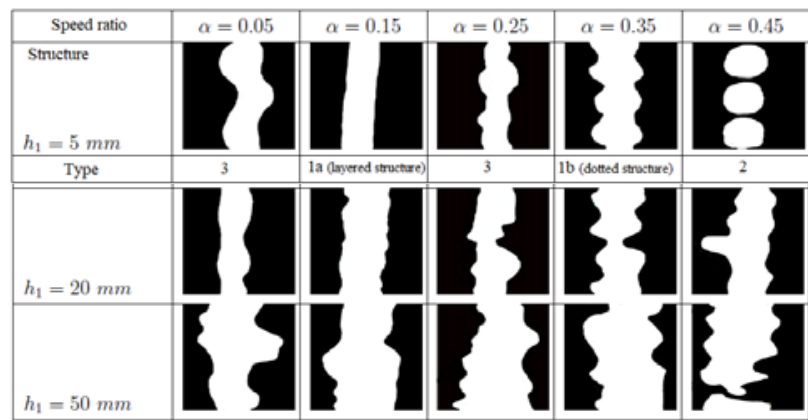

As obs erved from $t$ he $t$ able, $t$ he opt imum di stance between the nozzle and the deposited 1 ayer $h_{\mathrm{nl}}$ can b e derived. The contiguous and uniform structure as in type 1 (figure 4) can be achieved at a specific speed ratio.

If the speed ratio has a value of 0.15 (type 1a: layered structure) or 0.35 (type $1 \mathrm{~b}$ : dotted structure), th is results in a uniform contiguous structure as $r$ equired in an additive manufacturing process. Since type $1 \mathrm{a}$ has a layer periodicity length but type $1 \mathrm{~b}$ does not, there must be a transition between these $t$ wo types. This transition $z$ one can be determined experimentally, which is illustrated in figure 6 .

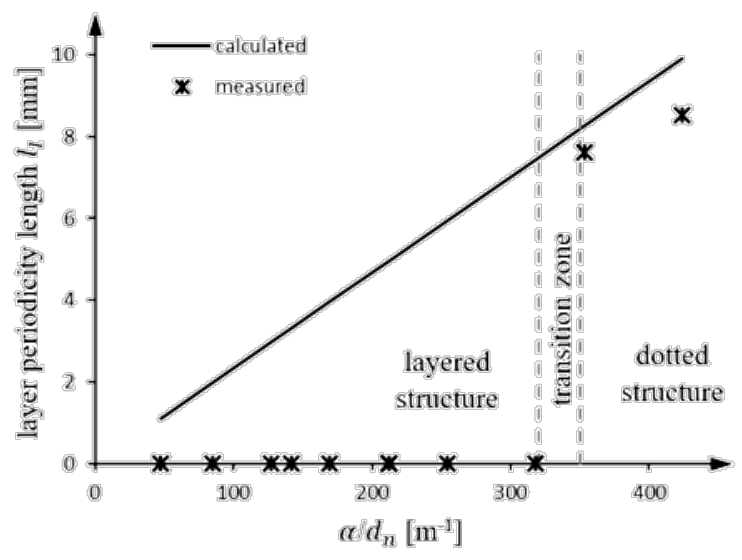

Figure 6. Measured and calculated values for the layer periodicity length.
There is a limit below which the measured periodicity lengths ar e $\mathrm{n}$ ot $\mathrm{i} \mathrm{n}$ acco rdance with $\mathrm{t}$ he $\mathrm{p}$ reviously calculated lengths. This limit ranges from $a / d_{\mathrm{n}}=320(\mathrm{~m}$ $\left.{ }^{1}\right)$ to $a / d_{\mathrm{n}}=350\left(\mathrm{~m}^{-1}\right)$ and constitutes the transition zone. Above th is 1 imit, the measured $v$ alues ap proximately conform with $t$ he $t$ heoretical $v$ alues. $T$ he $s$ urface structures of $\mathrm{t}$ he $\mathrm{d}$ eposited $\mathrm{l}$ ayers b elow a nd ab ove the limit differ significantly, as shown in figure 7. A layered structure ( with $\mathrm{n}$ o $\mathrm{p}$ eriodicity le ngth) $\mathrm{c}$ an $\mathrm{b}$ e $\mathrm{p}$ roduced when $a / d_{\mathrm{n}}$ is lower than the limit. To produce a dotted structure (with a d efined p eriodicity le ngth), $a / d_{\mathrm{n}}$ must be higher than the limit.
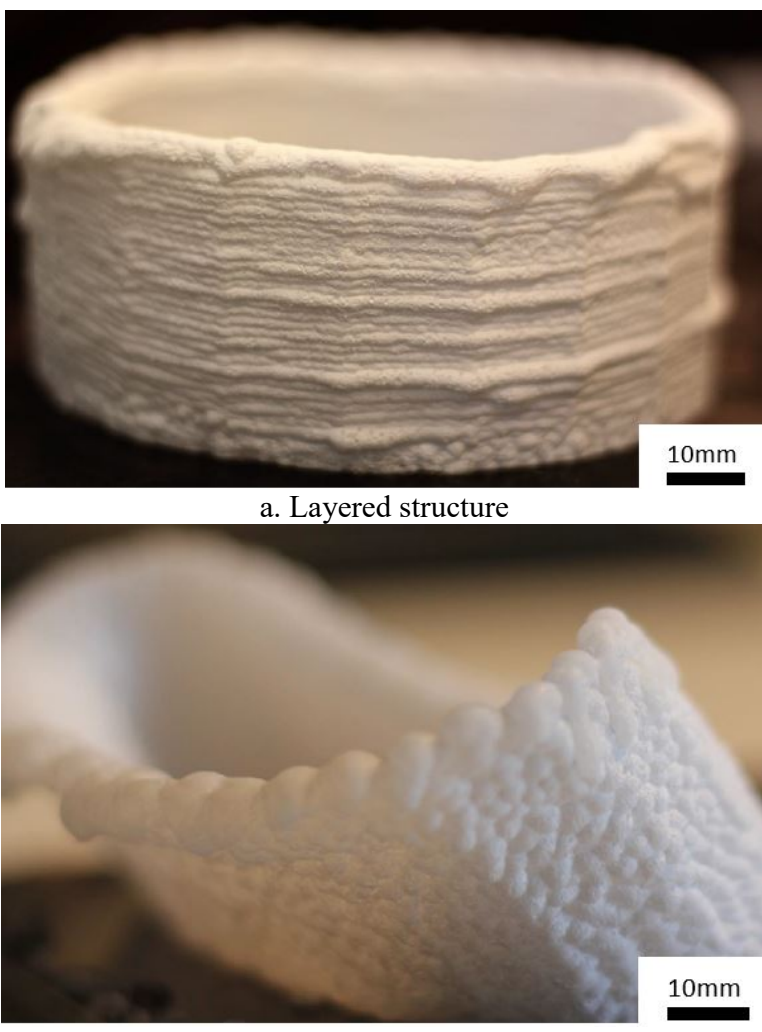

b. Dotted structure

Figure 7. Different types of surface structures: layered and dotted structure.

The cas e s tudy $\mathrm{p}$ resented in $\mathrm{t}$ his $\mathrm{p}$ aper $\mathrm{s}$ hows eight primary $p$ rocess $p$ arameters, which af fect the d eposited layers: feed $\mathrm{r}$ ate $v_{\mathrm{f}}$, nozzle o utlet $\mathrm{v}$ elocity $v_{\mathrm{n}}$, $\mathrm{d}$ istance between $\mathrm{n}$ ozzle an $\mathrm{d} \mathrm{t}$ he $\mathrm{d}$ eposited $\mathrm{l}$ ayer $h_{\mathrm{nl}}$, $\mathrm{n}$ ozzle diameter $d_{\mathrm{n}}$, temperatures $T_{1}, T_{2}, T_{3}$ and the concentration $w$. $\mathrm{T}$ heir ef fect of distance $\mathrm{b}$ etween nozzle an $\mathrm{d} t$ he deposited layer $h_{\mathrm{nl}}$, and b oth velocities $v_{\mathrm{n}}$ and $v_{\mathrm{f}}$ on the layer periodicity length $l_{1}$ was investigated in more detail.

Tests with $d$ ifferent speed $r$ atios $d$ emonstrated th at producing a contiguous and uniform surface s tructure is only possible with a speed ratio of $a=0.15$ or $a=0.35$, which can be controlled by the feed rate and the nozzle outlet velocity.

While $a / d_{\mathrm{n}}<3201 / m$ result in a layered structure using $a / d_{\mathrm{n}}>3501 / \mathrm{m}$ produces a d otted structure. For $\mathrm{s}$ the la tter, the theoretical layer p eriodicity le ngth $\mathrm{c}$ an $\mathrm{b} e$ calculated with a formula derived in this paper. 


\section{Conclusion and prospects}

This paper has focused on additive manufacturing of salt hydrates. A new additive manufacturing process was developed, $w$ hich $\mathrm{i} \mathrm{s}$ ba sed on $\mathrm{t}$ he de position of a subcooled 1 iquid s olution. T his novel pr ocess $h$ as be en named subcooled liquid printing (SLP) by the authors.

The a dvantages of using the SLP process is the possibility of producing di fferent s urface structures b y changing $t$ he $p$ rocess $p$ arameters $d$ uring t he o ngoing manufacturing $p$ rocess. $T$ he $u$ se $o$ f $s$ odium acet ate trihydrate aqueous s olution provides a dditional benefits, such a s no n-toxic b ehaviour a nd l ow-cost $\mathrm{p}$ urchasing. Therefore, $\mathrm{t}$ his ad ditive manufacturing $\mathrm{p}$ rocess $\mathrm{i} \mathrm{s}$ especially suitable for school and university environment.

To develop this SLP process to full technical maturity, other process parameters such as the temperatures $T_{1}, T_{2}$, $T_{3}$, and different concentrations $w$ must be in vestigated. Since the $\mathrm{s}$ ize o ft he manufactured o bjects depends significantly o $\mathrm{nt}$ he $\mathrm{s}$ trength o $\mathrm{ft}$ he material, f urther research in this area is also indispensable.

\section{References}

1. Gartner, "Hype Cycle for 3D Printing," (2018)

2. Wohler, "Wohlers Report," (2018)

3. M. Gebler, A. J. M. Schoot Uiterkamp, and C. Visser, "A global s ustainability p erspective o n $3 \mathrm{D}$ p rinting technologies," Energy Policy, vol. 74, no. C, pp. 158167, (2014)

4. G. C. Dumitrescu and I. A. T. Ă. Nase, "3D Printing - A N ew I ndustrial Revolution," Knowl. Horizons. Econ., vol. 8, no. 1, pp. 32-39, (2016)

5. M. Attaran, "The rise of 3-D printing: The advantages of ad ditive manufacturing o ver $t$ raditional manufacturing," Bus. Horiz., vol. 60, no. 5, pp. 677688, (2017)

6. C. W eller, R . K leer, a nd F . T. P iller, " Economic implications of $3 \mathrm{D}$ printing: Market structure models in lig ht of a dditive manufacturing r evisited," Int. J. Prod. Econ., vol. 164, pp. 43-56, (2015)

7. J. Y. Lee, J. An, and C. K. Chua, "Fundamentals and applications of 3D printing for novel materials," Appl. Mater. Today, vol. 7, pp. 120-133, (2017)

8. Y. Huang, M. C. Leu, J. Mazumder, and A. Donmez,
"Additive $\mathrm{m}$ anufacturing: $\mathrm{C}$ urrent state, $\mathrm{f}$ uture potential, gaps and needs, and recommendations," $J$. Manuf. Sci. Eng. Trans. ASME, vol. 137, no. 1, pp. 1$10,(2015)$

9. Z. Ma , H . B ao, a nd A . P . R oskilly, "Study o n solidification process of sodium acetate trihydrate for seasonal solar thermal e nergy storage," Sol. Energy Mater. Sol. Cells, v ol. 172, no . J uly, pp. $99-107$, (2017)

10. G. En glmair, C . Mo ser, S . F urbo, M . D annemand, and J. Fan, "Design and functionality of a s egmented heat-storage prototype utilizing stable supercooling of sodium acetate trihydrate in a solar heating system," Appl. Energy, v ol. 221, no . M arch, p p. 5 22-534, (2018)

11. W. F u et al., " Thermal $\mathrm{p}$ roperties an $\mathrm{d} t$ hermal conductivity enhancement of composite phase change material using s odium acet ate $t$ rihydrateurea/expanded $\mathrm{g}$ raphite $\mathrm{f}$ or $\mathrm{r}$ adiant $\mathrm{f}$ loor $\mathrm{h}$ eating system," Appl. Therm. Eng., vol. 138, no. March, pp. 618-626, (2018)

12. F. Y ang, G . Z hao, C . Z hou, a nd D . L in, "Phase change materials ( PCM) b ased co lds ource for selective freezing $3 \mathrm{D}$ p rinting of p orous materials," Int. J. Adv. Manuf. Technol., v ol. 95, n o. 5-8, pp. 2145-2155, (2018)

13. P. A. J. Donkers, L. C. Sögütoglu, H. P. Huinink, H. R. F ischer, an d O . C. G . Adan, "A r eview o f s alt hydrates for $\mathrm{s}$ easonal $\mathrm{h}$ eat $\mathrm{s}$ torage $\mathrm{i} \mathrm{nd}$ omestic applications," Appl. Energy, vol. 199, pp. 45-68, (2017)

14. J. Pereira da Cunha and P. Eames, "Thermal energy storage for low and medium temperature applications using $\mathrm{p}$ hase c hange materials - A r eview," Appl. Energy, vol. 177, pp. 227-238, (2016)

15. P. Novotný and O. Söhnel, "Densities of Binary Aqueous S olutions of 306 I norganic S ubstances," J. Chem. Eng. Data, vol. 33, no. 1, pp. 49-55, (1988)

16. B. Minofar, P. Jungwirth, M. R. Das, W. Kunz, and S. Mahiuddin, "Propensity of formate, acetate, benzoate, and $\mathrm{p}$ henolate for $\mathrm{t}$ he a queous s olution/vapor interface: $\mathrm{S}$ urface $\mathrm{t}$ ension $\mathrm{m}$ easurements an $\mathrm{d}$ molecular dynamics simulations," J. Phys. Chem. C, vol. 111, no. 23 , pp. 8242-8247, (2007) 